\title{
Erratum to: Simulation of Hydrogen Auto-Ignition in a Turbulent Co-flow of Heated Air with LES and CMC Approach
}

\section{Ivana Stanković • Antonios Triantafyllidis · Epaminondas Mastorakos · Chris Lacor • Bart Merci}

Published online: 14 September 2010

(C) Springer Science+Business Media B.V. 2010

\section{Erratum to: Flow Turbulence Combust (2010) DOI 10.1007/s10494-010-9277-0}

Unfortunately an error was introduced during the typesetting of this article. Figure 11 should have been displayed as follows:
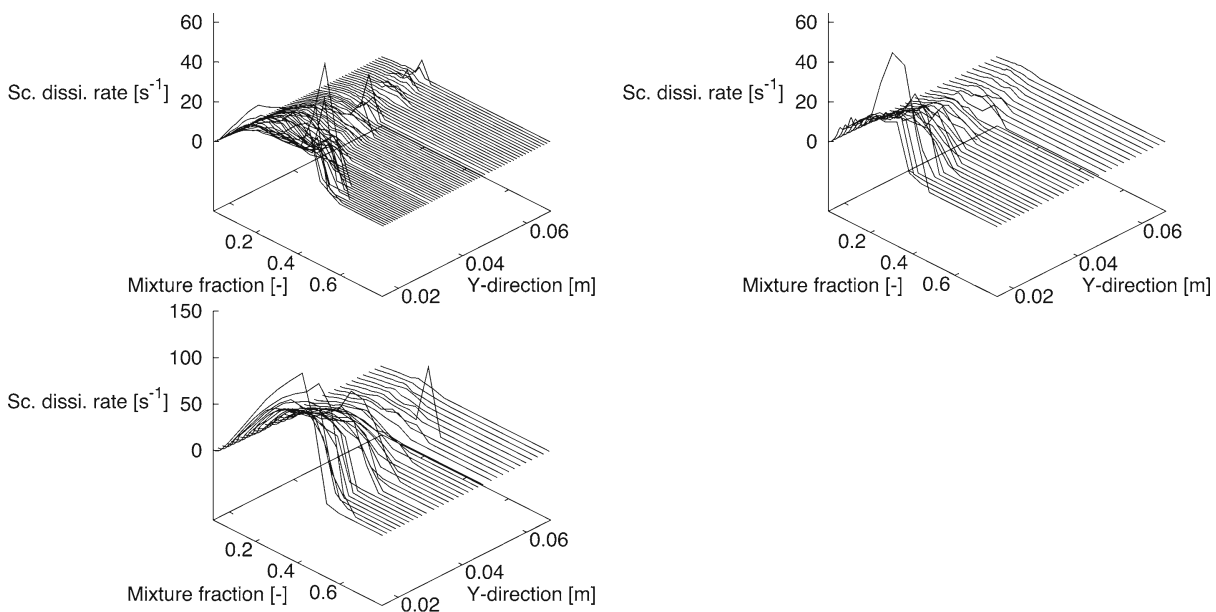

Fig. 11 Time averaged conditional scalar dissipation rate $(\widetilde{N \mid \eta})$ for case 1 (top left), case 2 (top right), case 3 (bottom)

The online version of the original article can be found at http://dx.doi.org/10.1007/s10494-010-9277-0.

I. Stanković $(\bowtie) \cdot$ B. Merci

Department of Flow, Heat and Combustion Mechanics, Ghent University,

St.-Pietersnieuwstraat 41, 9000 Ghent, Belgium e-mail: Ivana.Stankovic@UGent.be

A. Triantafyllidis $\cdot$ E. Mastorakos

Hopkinson Laboratory, Engineering Department, Cambridge University, Cambridge, UK

C. Lacor

Department of Mechanical Engineering, Vrije Universiteit Brussel,

Brussel, Belgium 